\title{
IncRNA SNHG4 promotes cell proliferation, migration, invasion and the epithelial-mesenchymal transition process via sponging miR-204-5p in gastric cancer
}

\author{
SHIMEI WANG ${ }^{1 *}$, WEI ZHU ${ }^{2 *}$, JI QIU $^{3}$ and FEI CHEN ${ }^{3}$ \\ ${ }^{1}$ Department of Gastroenterology, Zhuji People's Hospital of Zhejiang Province; \\ ${ }^{2}$ Department of General Surgery, Zhuji Central Hospital; ${ }^{3}$ Department of Gastroenterology, \\ Zhuji People's Hospital of Zhejiang Province, Shaoxing, Zhejiang 311800, P.R. China
}

Received November 28, 2019; Accepted September 4, 2020

DOI: $10.3892 / \mathrm{mmr} .2020 .11724$

\begin{abstract}
Long non-coding (lnc)RNAs and microRNAs (miRNAs/miRs) have physiological and pathological functions in various diseases, including gastric cancer (GC). The current study explored the association between IncRNA small nucleolar RNA host gene 4 (SNHG4) and miR-148a-3p, and their functions in GC cells. SNHG4 expression and overall survival data were analyzed using bioinformatics, and the interaction of SNHG4 and miR-148a-3p was predicted using starBase and confirmed via a dual-luciferase reporter assay. Cell viability, colony formation ability and apoptosis rate were detected using Cell Counting Kit-8, colony formation and flow cytometry assays, respectively. Cell migration and invasion were determined via wound-healing and Transwell assays. mRNA and protein expression levels were determined via reverse transcription-quantitative PCR and western blotting. The results demonstrated that in GC tissues and cell lines, SNHG4 was highly expressed, while miR-204-5p expression was decreased, and that the expression levels of SNHG4 and miR-204-5p were negatively correlated. The downregulated expression of SNHG4 decreased the effects of miR-204-5p inhibitor on promoting cell proliferation, migration, invasion and epithelial-mesenchymal transition, but enhanced the inhibitory effect of miR-204-5p on GC cell apoptosis. The findings of the current study revealed the potential mechanism of the SNHG4-miR-204-5p pathway in GC, which may be conducive to the development of novel drugs against GC growth.
\end{abstract}

Correspondence to: Dr Shimei Wang, Department of Gastroenterology, Zhuji People's Hospital of Zhejiang Province, 9 Jianmin Road, Taozhu Street, Zhuji, Shaoxing, Zhejiang 311800, P.R. China

E-mail: shimei_wa@163.com

*Contributed equally

Key words: SNHG4, microRNA-204-5p, hallmarks of cancer, gastric cancer, mechanism

\section{Introduction}

Gastric cancer (GC) is one of the most frequent types of cancer and the second leading cause of cancer-associated deaths worldwide (1). According to recorded statistics from 2012, $>70 \%$ of new cases of GC occured in developing countries, primarily in Asia, Central Europe, Eastern Europe and Latin America $(2,3)$. GC results in $>951,000$ new cases and 723,000 deaths per year worldwide (3). Tumor metastasis, which is responsible for $90 \%$ of all cancer-associated deaths, is a multi-step process of biological cascades that ultimately leads to the spread of tumor cells to different tissues $(4,5)$. Early surgical treatment, targeted chemotherapy and immunotherapy are widely applied in managing the metastasis and progression of GC, but the results are often unsatisfactory (6-8). Tumor cells will develop multi-drug resistance to chemotherapy, which is a key factor affecting the therapeutic effect on numerous types of cancer, including GC (9). Therefore, further exploration of the pathogenesis of GC and development of a more effective treatment is necessary.

The human genome consists of $>98 \%$ non-coding regions and therefore the remaining $<2 \%$ of the human genome are translated into proteins; most non-coding regions are directly transcribed into RNAs (10-12). These RNAs cannot be translated into proteins and are therefore considered as non-coding RNAs (ncRNAs) (10-12). The ncRNA family members are numerous and highly diverse, and can be easily divided into short ncRNAs ( $<200$ nucleotides in length) and long ncRNAs (lncRNAs; $>200$ nucleotides in length) according to RNA length. The most representative and the most studied ncRNAs are microRNAs (miRNAs/miRs) and lncRNAs (13-17). A number of studies have demonstrated a mutual regulation between IncRNAs and miRNAs, and different regulatory forms of the two in interaction affect various diseases, including GC (13-17).

Li et al (18) demonstrated that the IncRNA small nucleolar RNA host gene 4 (SNHG4) can sponge miR-148a-3p to exert a cancer-promoting function in cervical cancer. Chen et al (19) demonstrated that miR-204-5p acts as an antitumor factor in GC, suppressing GC progression. The current study aimed to explore the association between SNHG4 and miR-148a-3p in GC cells. 


\section{Materials and methods}

Ethics approval. All experiments were approved by the Ethics Board of Zhuji People's Hospital (Shaoxing, China). A total of 53 patients diagnosed with GC by gastroscopy and pathological examination were recruited in the current study. All patients in the present study provided written informed consent and their pathophysiological characteristics (age, sex, histology differentiation, borrmann type, tumour location, lymph node metastasis, tumour invasion and TNM stage) (20) were collected (Table I). None of the enrolled patients received chemotherapy, radiotherapy or targeted therapy before radical surgery. Samples from GC tissues and adjacent non-tumor tissues ( $\geq 2 \mathrm{~cm}$ from the tumour margin) were collected from the 53 patients with GC (age range, 38-85 years; mean age, 61 years) who underwent radical gastrectomy at Zhuji People's Hospital between April 2018 and June 2019. All the samples were frozen in liquid nitrogen immediately after the resection and stored at $-80^{\circ} \mathrm{C}$ until use.

Bioinformatics. The expression levels of SNHG4 in GC and normal tissues was predicted using starBase v3.0 (starbase. sysu.edu.cn). The patients were divided into high SNHG4 and low SNHG4 groups according to the median (median value, 41). The overall survival rate of patients with low or high SNHG4 expression was plotted using Kaplan-Meier (21). The interaction between SNHG4 and miR-204-5p was predicted using TargetScan v7.2 (www.targetscan.org).

Cell culture. Human gastric epithelial cell line GES-1 and GC cell lines (SNU719, AGS and HGC-27) were purchased from The Cell Bank of Type Culture Collection of the Chinese Academy of Sciences. GES-1 and HGC-27 cells were cultured in RPMI-1640 medium (cat. no. 21875091; Thermo Fisher Scientific, Inc.), SNU719 cells were cultured in DMEM (cat. no. D0819; Sigma-Aldrich; Merck KGaA) and AGS cells were cultured in Ham's F-12K (Kaighn's) medium (cat. no. 21127022; Thermo Fisher Scientific, Inc.). The cells were supplemented with 10\% FBS (cat. no. F8192) and penicillin-streptomycin reagent (cat. no. V900929) (both from Sigma-Aldrich; Merck $\mathrm{KGaA}$ ), and cultured at $37^{\circ} \mathrm{C}$ with $5 \% \mathrm{CO}_{2}$.

Experimental design. According to the expression levels of SNHG4, AGS and HGC-27 cell lines were used in subsequent experiments. To explore the association between SNHG4 and miR-204-5p, AGS and HGC-27 cells were divided into different groups depending on their treatment. Cells were treated with short interfering (si)SNHG4 (Shanghai GenePharma Co., Ltd.) plus miR-204-5p inhibitor control (IC; non-targeting scrambled control; Shanghai GenePharma Co., Ltd.), siSNHG4 plus miR-204-5p inhibitor (I; Shanghai GenePharma Co., Ltd.), siSNHG4 negative control (siNC; non-targeting scrambled control; Shanghai GenePharma Co., Ltd.) plus miR-204-5p IC and siNC plus miR-204-5p I, corresponding to the siSNHG4+IC, siSNHG4+I, siNC+IC and siNC+I groups, respectively. The sequences of siRNAs and miRNAs were as follows: siSNHG4, 5'-UAUUUCCUCCCUUCAGAUGGG-3'; siNC, 5'-UUCUCCGAACGUGUCACGUTT-3'; miR-204-5p I, 5'-AGGCAUAGGAUGACAAAGGGAA-3'; and miR-204-5p IC, 5'-UCUACUCUUUCUAGGAGgUUGUGA-3'. For transfection, AGS and HGC-27 cells ( $2 \times 10^{5}$ cells) were seeded in 6-well plates and incubated at $37^{\circ} \mathrm{C}$ for $24 \mathrm{~h}$. When cell confluence reached $80-90 \%$, the cells were transfected with siSNHG4 (50 nM), siNC (50 nM), miR-204-5p I (100 nM) and miR-204-5p IC (100 nM) using Lipofectamine ${ }^{\circledR} 3000$ (cat. no. L3000015; Thermo Fisher Scientific, Inc.) according to the manufacturer's protocol. Transfection efficiency was monitored using quantitative (q)PCR after $48 \mathrm{~h}$. At $48 \mathrm{~h}$ post-transfection, cells were used for subsequent experiments.

Reverse transcription (RT)-qPCR. Following the collection of GC tissues from the patients, total RNA was extracted from samples and GC cells $\left(5 \times 10^{6}\right)$ using TRIzol ${ }^{\circledR}$ reagent (cat. no. 15596018; Thermo Fisher Scientific, Inc.) according to the manufacturer's protocol and used to detect the expression levels of SNHG4 and miR-204-5p in adjacent normal tissues (ANTs), GC tissues and transfected cells. The same procedures were performed in GES-1, SNU719, AGS and HGC-27 cells. cDNA was synthesized using PrimeScript RT reagent kit (Takara Biotechnology Co., Ltd.) according to the manufacturer's protocols. qPCR was performed in a IQ5 thermocycler (Bio-Rad Laboratories, Inc.) under the following conditions: $90 \mathrm{sec}$ at $95^{\circ} \mathrm{C}, 30 \mathrm{sec}$ at $95^{\circ} \mathrm{C}, 20 \mathrm{sec}$ at $65^{\circ} \mathrm{C}$ and $30 \mathrm{sec}$ at $72^{\circ} \mathrm{C}$, for 40 cycles. The reaction system was composed of $8 \mu 1$ 2X SYBR Green master mix [cat. no. 4913850001; Roche Diagnostics (Shanghai) Co., Ltd.], $1 \mu \mathrm{l}$ forward primer $(10 \mu \mathrm{M}), 1 \mu \mathrm{l}$ reverse primer $(10 \mu \mathrm{M}), 10 \mu \mathrm{l}$ cDNA template and $5 \mu$ l double-distilled $\mathrm{H}_{2} \mathrm{O}$. Relative expression levels of each sample were calculated using the $2^{-\Delta \Delta C q}$ method (22). miRNA and mRNA expression levels were normalized to the internal reference genes U6 and GAPDH, respectively. The primers are listed in Table II. The experiment was repeated three times independently.

Dual-luciferase reporter assay. The verification of the interaction between SNHG4 and miR-204-5p was performed using a dual-luciferase reporter assay. SNHG4 mutation was created using the Quick-Change Site-Directed Mutagenesis kit (Agilent Technologies, Inc.). The pRL-TK plasmid (Promega Corporation) was transfected with miR-204-5p I using Lipofectamine 3000 . At $48 \mathrm{~h}$ post-transfection, the dual-Glo luciferase assay kit (Promega Corporation) was used to determine the relative luciferase activities of AGS and HGC-27 cells. Relative luciferase activity was normalized to Renilla luciferase activity.

Cell Counting Kit (CCK)-8. Following cell transfection, AGS and HGC-27 cells ( $1 \times 10^{6}$ cells/well) were cultured for 24,48 and $72 \mathrm{~h}$ in 6-well plates and incubated with $10 \mu \mathrm{l}$ CCK-8 reagent (cat. no. 96992-100TESTS-F; Sigma-Aldrich; Merck KGaA) at $37^{\circ} \mathrm{C}$ for $2 \mathrm{~h}$. Finally, the optical density (OD) at $450 \mathrm{~nm}$ was read and recorded using a Multiskan microplate reader (Thermo Fisher Scientific, Inc.).

Colony formation assay. Following cell transfection, the cells were harvested at $1 \times 10^{6}$ cells $/ \mathrm{ml}$ and seeded onto plates for 14 days at $37^{\circ} \mathrm{C}$ with $5 \% \mathrm{CO}_{2}$ to assess colony formation. After 100-120 clones were formed, the colonies were stained with $0.2 \%$ crystal violet for $30 \mathrm{~min}$ at room temperature after fixation with $1 \mathrm{ml}$ methanol for $15 \mathrm{~min}$ at room temperature. 
Table I. Association between SNHG4 expression and clinical characteristics.

\begin{tabular}{|c|c|c|c|c|}
\hline \multirow[b]{2}{*}{ Variable } & \multicolumn{2}{|c|}{$\begin{array}{c}\text { Relative SNHG4 } \\
\text { expression, } \mathrm{n}\end{array}$} & \multirow[b]{2}{*}{$\chi^{2}$} & \multirow[b]{2}{*}{ P-value } \\
\hline & $\begin{array}{l}\text { Low } \\
(\mathrm{n}=27)\end{array}$ & $\begin{array}{l}\text { High } \\
(\mathrm{n}=26)\end{array}$ & & \\
\hline Age, years & & & 0.573 & 0.449 \\
\hline$\geq 60$ & 16 & 18 & & \\
\hline$<60$ & 11 & 8 & & \\
\hline Sex & & & 0.172 & 0.678 \\
\hline Male & 14 & 12 & & \\
\hline Female & 13 & 14 & & \\
\hline Histological differentiation & & & 3.627 & 0.163 \\
\hline Well & 9 & 2 & & \\
\hline Moderate & 11 & 10 & & \\
\hline Poor & 7 & 14 & & \\
\hline Borrmann type & & & 2.051 & 0.359 \\
\hline Early stage & 5 & 2 & & \\
\hline I+II type & 9 & 7 & & \\
\hline III+IV type & 13 & 17 & & \\
\hline Tumor location & & & 1.672 & 0.433 \\
\hline Upper stomach & 6 & 5 & & \\
\hline Middle stomach & 9 & 10 & & \\
\hline Lower stomach & 7 & 5 & & \\
\hline Mixed & 5 & 6 & & \\
\hline Lymph node metastasis & & & 8.578 & 0.003 \\
\hline Yes & 10 & 20 & & \\
\hline No & 17 & 6 & & \\
\hline Tumor invasion (AJCC) & & & 8.312 & 0.004 \\
\hline Tis- $\mathrm{T}_{2}$ & 19 & 8 & & \\
\hline $\mathrm{T}_{3}-\mathrm{T}_{4}$ & 8 & 18 & & \\
\hline TNM stage (AJCC) & & & 13.746 & $<0.001$ \\
\hline I-II & 21 & 7 & & \\
\hline III-IV & 6 & 19 & & \\
\hline
\end{tabular}

SNHG4, small nucleolar RNA host gene 4; AJCC, American Joint Committee on Cancer.

Finally, the number of colonies (cell clusters containing $\geq 5$ cells) were observed and counted under a light microscope (magnification, x1). Colony formation rate (\%) was calculated according to the following formula: (number of clones/cells inoculated) x100.

Flow cytometry. At $48 \mathrm{~h}$ post-transfection, cell apoptosis was determined following transfection. AGS and HGC-27 cells were diluted to $1 \times 10^{6}$ cells $/ \mathrm{ml}$ after $48 \mathrm{~h}$ culture at $37^{\circ} \mathrm{C}$, washed with PBS and then mixed with $200 \mu \mathrm{l}$ binding buffer. Following the instructions of the Annexin V-FITC kit (Sigma-Aldrich; Merck KGaA), $5 \mu 1$ PI and $10 \mu 1$ FITC-labeled Annexin V was added to cells for $15 \mathrm{~min}$ at room temperature. The cells were then resuspended in $300 \mu \mathrm{l}$ binding buffer and then subjected
Table II. Primers used in the present study.

\begin{tabular}{ll}
\hline Primer name & \multicolumn{1}{c}{ Sequence (5'-3') } \\
\hline miR-204-5p & F CCTTTGTCATCCTATGCC \\
miR-204-5p & R GAACATGTCTGCGTATCTC \\
lncRNA SNHG4 & F GCAGGTGACAGTCTGCATGT \\
lncRNA SNHG4 & R TTTTAAGTCCCCTACCCCCATC \\
GAPDH & F CGCTTCACGAATTTGCGTGTCAT \\
GAPDH & R GAAGATGGTGATGGGATTTC \\
U6 & F GCTTCGGCAGCACATATACTAAAAT \\
U6 & R CGCTTCACGAATTTCGTGTCAT
\end{tabular}

miR, microRNA; lncRNA, long non-coding RNA; F, forward; $\mathrm{R}$, reverse.

to flow cytometry (BD FACSVerse ${ }^{\mathrm{TM}}$; BD Biosciences) and analyzed using FlowJo software (version 10.0; FlowJo LLC) to determine cell apoptosis. The rate of apoptosis was calculated as the sum of early and late apoptosis.

Wound-healing assay. At $48 \mathrm{~h}$ post-transfection, AGS and HGC-27 cells $\left(1 \times 10^{6}\right.$ cells $\left./ \mathrm{ml}\right)$ were harvested into the dishes to create a monolayer. At $90-100 \%$ confluence, When the monolayers of cells were grown to $\sim 90-100 \%$ confluency, a gap in the center of the layer was made using a 200- $\mu$ l pipette tip and the cells were maintained in serum-free RPMI-1640 medium with $5 \% \mathrm{CO}_{2}$ at $37^{\circ} \mathrm{C}$. After $48 \mathrm{~h}$, the floating cells were removed by washing the cells with PBS. The distance of cell migration was determined by the mean value of the width of the gap between the top, middle and bottom of the wound. The wounds were observed in five fields of view using a light microscope (magnification, $\mathrm{x} 100$ ).

Transwell assay. A Transwell assay was performed for determining cell invasion. As aforementioned, AGS and HGC-27 cells $\left(1 \times 10^{6}\right.$ cells $\left./ \mathrm{ml}\right)$ were harvested and seeded with serum-free RPMI-1640-medium into the upper chamber of a 8- $\mu \mathrm{m}$ Transwell insert pre-coated with Matrigel (BD Biosciences). In the bottom chamber, $300 \mu 1$ RPMI-1640 medium with $10 \%$ FBS was added. The cells were incubated for $48 \mathrm{~h}$ with $5 \% \mathrm{CO}_{2}$ at $37^{\circ} \mathrm{C}$ for the invasion test. Finally, the cells that had invaded into the bottom chamber were washed with PBS and fixed with $4 \%$ paraformaldehyde for 15 min at room temperature and then stained with $0.2 \%$ crystal violet for $10 \mathrm{~min}$ at room temperature for observation under a light microscope (magnification, $\mathrm{x} 250$ ).

Western blot analysis. The protein expression levels of E-cadherin (cad), N-cad and Snail of the cells transfected with siSNHG4 or miR-204-5p I were detected. A total of $1 \times 10^{6}$ cells/ml (AGS and HGC-27 cells) were harvested and lysed using RIPA lysis buffer (cat. no. R0278; Sigma-Aldrich; Merck KGaA) plus protease inhibitor (cat. no. S8830; Sigma-Aldrich; Merck KGaA) to obtain the total protein. Protein concentration was measured using BCA regent (Sigma-Aldrich; Merck KGaA). Protein samples ( $40 \mu \mathrm{g} /$ lane) were separated via $12 \%$ SDS-PAGE at $90 \mathrm{~V}$ for $2 \mathrm{~h}$, then transferred to PVDF 
A SNHG4 with 375 cancer and 32 normal samples in STAD

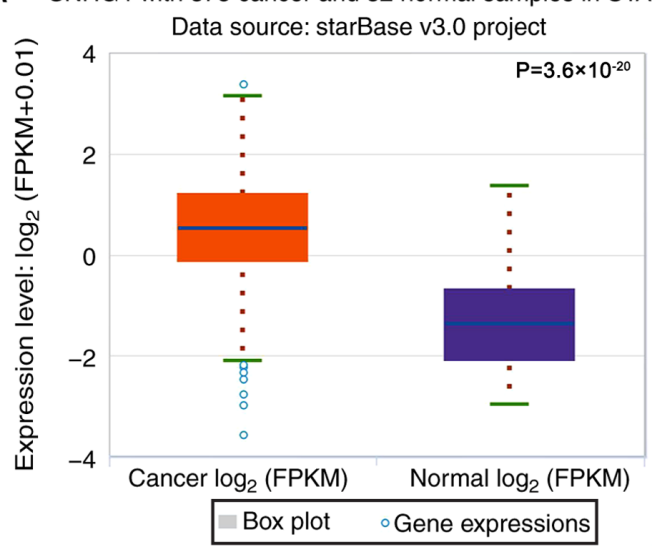

C

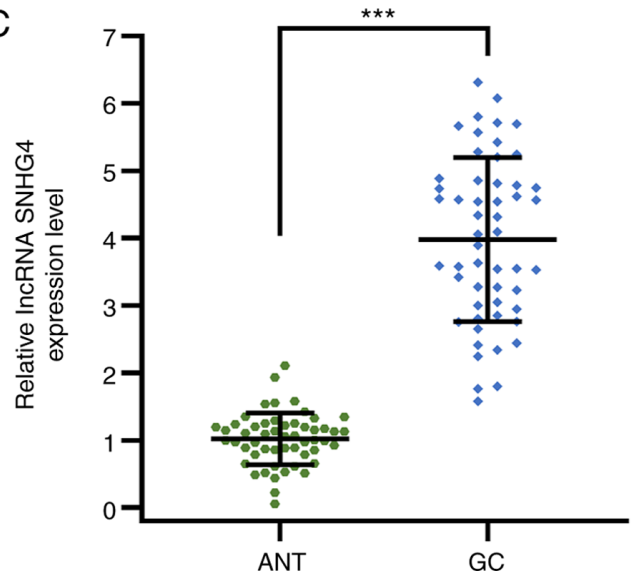

B

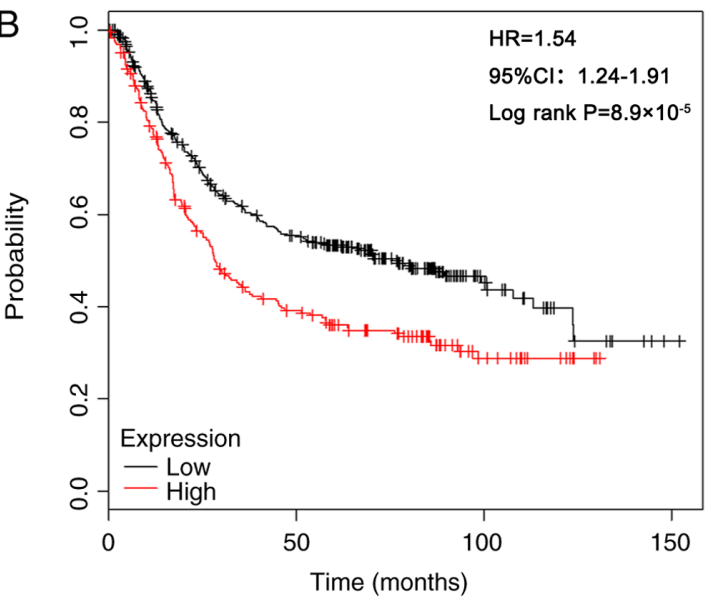

D

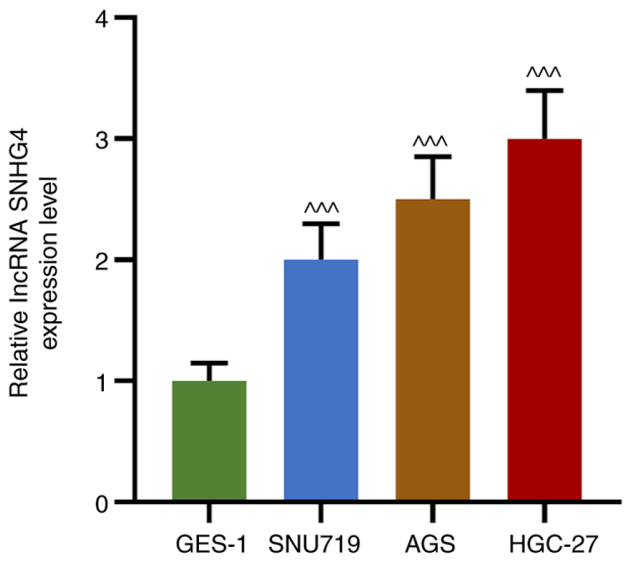

Figure 1. SNHG4 is upregulated in GC tissues and cell lines. (A) SNHG4 expression in 375 cancer and 32 normal samples in STAD from starBase v3.0 database. (B) Overall survival rate of patients with low or high SNHG4 expression. (C) Relative SNHG4 expression levels in ANTs or GC tissues from the 53 enrolled patients in Zhuji People's Hospital. (D) Relative SNHG4 expression in GES-1, SNU719, AGS and HGC-27 cell lines. Bars indicate the mean \pm standard deviation. ${ }^{* * *} \mathrm{P}<0.001$ vs. ANT; ${ }^{\wedge \wedge} \mathrm{P}<0.001$ vs. GES-1. SNHG4, small nucleolar RNA host gene 4; GC, gastric cancer; ANT, adjacent normal tissue; HR, hazard ratio; IncRNA, long non-coding RNA; STAD, stomach adenocarcinoma; FPKM, Fragments per Kilobase Million.

membranes and blocked using 5\% skimmed milk for $1 \mathrm{~h}$ at room temperature. Antibodies against proliferating cell nuclear antigen (PCNA; cat. no. ab92552; Abcam; 1:1,000; 29 kDa), cyclin D1 (cat. no. ab16663; Abcam; 1:200; 33 kDa), E-cad (cat. no. ab40772; Abcam; 1:1,000; 97 kDa), N-cad (cat. no. ab76057; Abcam; 1:1,000; 100 kDa), Snail (cat. no. ab216347; Abcam; $1: 1,000 ; 29 \mathrm{kDa}$ ) and GAPDH (cat. no. ab181602; Abcam; $1: 1,000 ; 36 \mathrm{kDa}$ ) were mixed in $5 \%$ skimmed milk and incubated with the membrane overnight at $4^{\circ} \mathrm{C}$. After washing with PBS-Tween $(0.1 \%$ Tween), primary antibodies were detected using an HRP-conjugated goat anti-rabbit secondary antibody (cat. no. ab205718; Abcam; 1:2,000) at room temperature for $2 \mathrm{~h}$, and the protein signals were developed using SignalFire ${ }^{\mathrm{TM}}$ ECL Reagent (cat. no. 6883; Cell Signaling Technology, Inc.). Protein expression levels were quantified using ImageJ software (v1.8.0; National Institutes of Health), with GAPDH as the loading control.

Statistical analysis. Data are presented as the mean \pm SD of three independent experiments. The data were analyzed using GraphPad Prism 8.0 (GraphPad Software, Inc.). The statistical differences with regard to the overall survival rate and pathophysiological characteristics among patients with low or high SNHG4 expression were analyzed using the log-rank and $\chi^{2}$ tests, respectively. The correlation between the expression levels of SNHG4 and miR-204-5p was analyzed using Pearson's correlation analysis. An unpaired Student's t-test was used to analyze the statistical difference between two groups. One-way ANOVA followed by Tukey's post hoc test was conducted to measure the statistical difference among multiple groups, and paired Student's t-test was used to compare the data between tumor and adjacent non-tumor tissues. $\mathrm{P}<0.05$ was considered to indicate a statistically significant difference.

\section{Results}

SNHG4 is upregulated in GC tissues and cell lines. To examine the role of SNHG4 in GC, SNHG4 expression was measured in GC tissues and cell lines. In GC tissues, SNHG4 was highly expressed and high SNHG4 expression was associated with a lower survival rate compared with low SNHG4 expression (P<0.001; Fig. 1A-C). Similarly, SNHG4 expression in SNU719, AGS and HGC-27 cells was significantly upregulated compared with that in GES-1 cells, which are normal gastric epithelial cells $(\mathrm{P}<0.001$; Fig. 1D). In addition, as shown in Table I, SNHG4 expression was significantly associated with lymph node metastasis, tumor invasion and TNM stage. Therefore, the data suggested that SNHG4 may promote GC development. 
A

\begin{tabular}{|c|c|}
\hline SNHG4-WT & Target: 5 ' uguUAUCAGCUGCUAAAAGGGAg 3 ' \\
\hline & 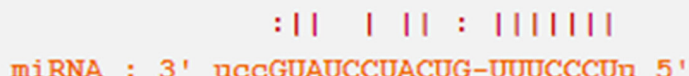 \\
\hline hsa-miR-204-5p & miRNA : 3' uccGUAUCCUACUG-UUUCCCUu \\
\hline SNHG4-MUT & get: 5 ' uguUGCCAUCCACUACCGUUCCg \\
\hline
\end{tabular}
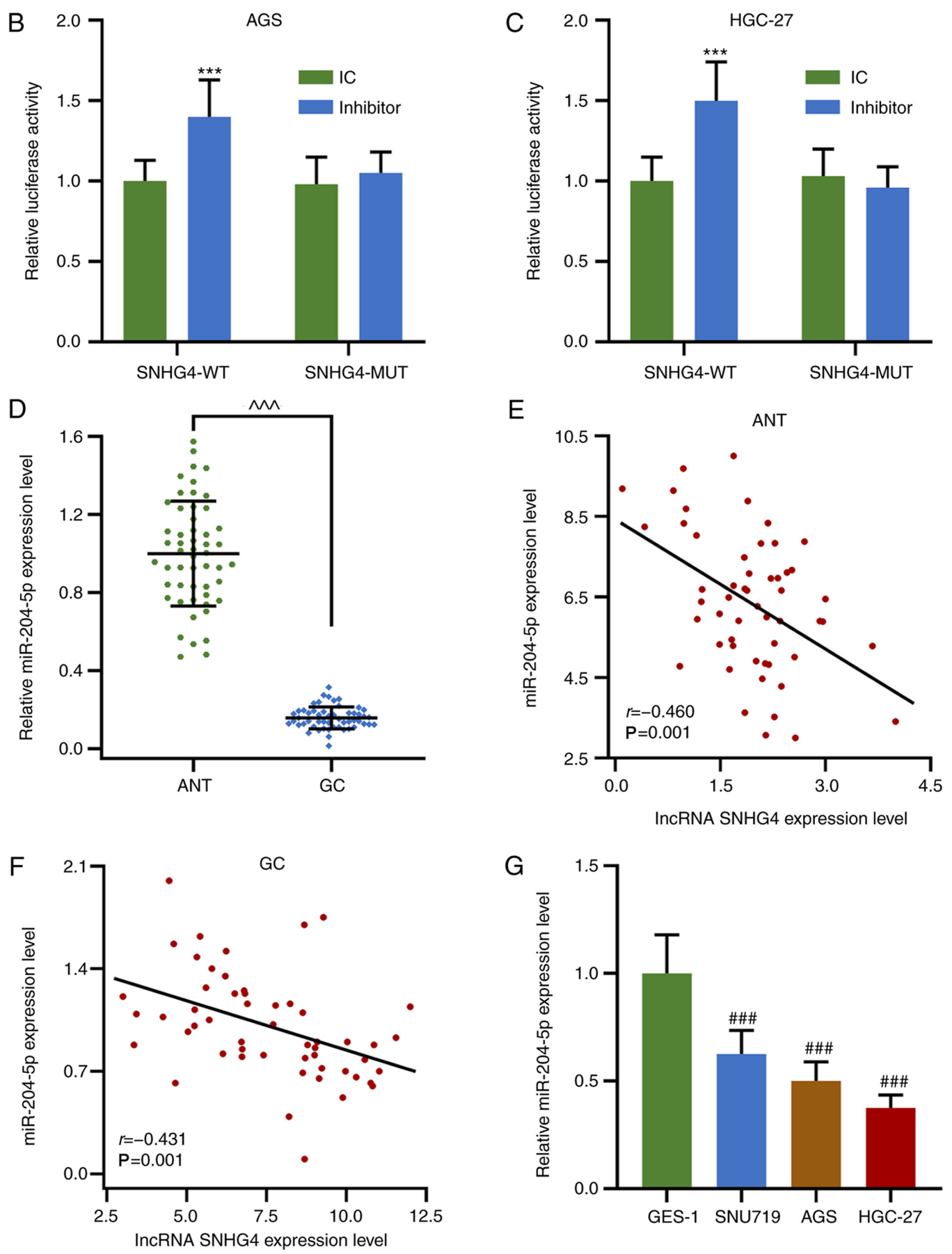

Figure 2. miR-204-5p expression is downregulated in GC tissues and cell lines, and its expression levels are negatively correlated with those of SNHG4. (A) Possible complementary sequences in SNHG4-WT and miR-204-5p. Relative luciferase activity in (B) AGS and (C) HGC-27 cells treated with or without miR-204-5p inhibitor when SNHG4 sequence was WT or MUT. (D) Relative miR-204-5p expression levels in ANTs or GC tissues. Correlation between the expression levels of SNHG4 and miR-204-5p in (E) ANT and (F) GC tissues. (G) Relative miR-204-5p expression levels in GES-1, SNU719, AGS and HGC-27 cell lines. Bars indicate the mean \pm standard deviation. ${ }^{* * *} \mathrm{P}<0.001$ vs. IC; ${ }^{\wedge \wedge} \mathrm{P}<0.001$ vs. ANT; ${ }^{\# \# \#} \mathrm{P}<0.001$ vs. GES-1. SNHG4, small nucleolar RNA host gene 4; GC, gastric cancer; miR, microRNA; WT, wild-type; MUT, mutant; ANT, adjacent normal tissues; IC, inhibitor control.

miR-204-5p expression is suppressed in GC tissues and cell lines, and is negatively correlated with SHNG4 expression.
miR-204-5p was predicted and verified to interact with SNHG4 by bioinformatics and a dual-luciferase reporter 

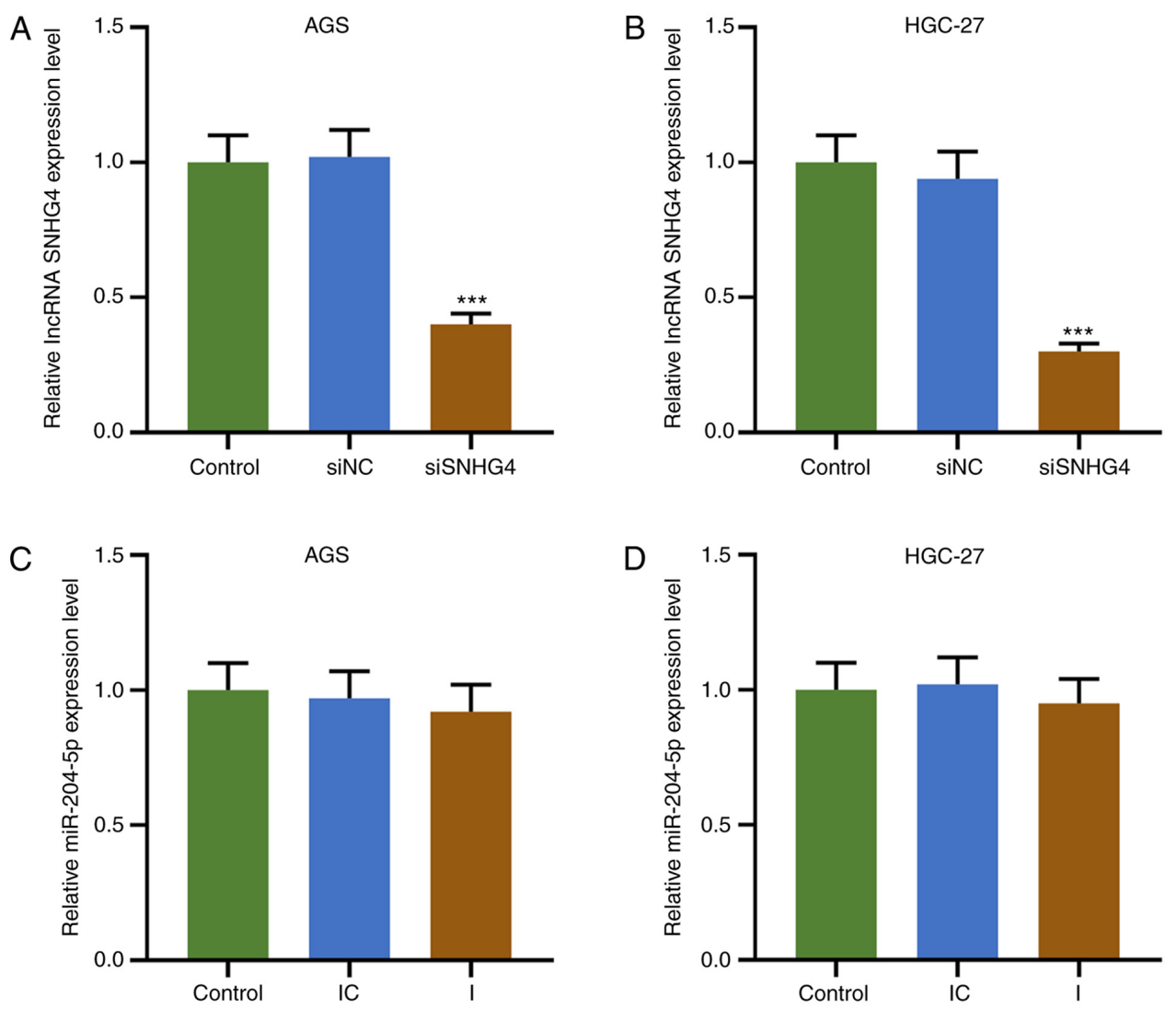

Figure 3. Transfection efficiency of siSNHG4 and miR-204-5p inhibitor in gastric cancer cells. Relative SNHG4 expression levels in control (untransfected), siNC and siSNHG4 groups in (A) AGS and (B) HGC-27 cells. Relative miR-204-5p expression level in control, IC and I groups in (C) AGS and (D) HGC-27 cells. ${ }^{* * *} \mathrm{P}<0.001$ vs. siNC. SNHG4, small nucleolar RNA host gene 4; miR, microRNA; si, short interfering; IC, inhibitor control; I, inhibitor; NC, negative control; lncRNA, long non-coding RNA.

assay, and the expression levels of miR-204-5p in GC were investigated. Notably, miR-204-5p shared a complementary sequence with SNHG4, and the dual-luciferase reporter assay demonstrated that miR-204-5p inhibitor increased the relative luciferase activities of SNHG4-WT in AGS and HGC-27 cells compared with the miR-204-5p inhibitor control group ( $\mathrm{P}<0.001$; Fig. 2A-C). In addition, miR-204-5p expression in GC tissues and cell lines (SNU719, AGS and HGC-27) was significantly decreased compared with that in ANTs or GES-1 cells, respectively ( $\mathrm{P}<0.001 ;$ Fig. 2D and G). Notably, in ANTs and GC tissues, the expression levels of miR-204-5p and SNHG4 were found to be negatively correlated (Fig. 2E and F). The results indicated that SNHG4 may exert its regulatory function via suppressing miR-204-5p expression.

Downregulation of SNHG4 expression reverses the effects of miR-204-5p inhibitor on the proliferation and apoptosis of $G C$ cells. To understand the association between SNHG4 and miR-204-5p in GC, cell viability, colony formation and apoptosis were evaluated when SNHG4 or miR-204-5p expression was downregulated in AGS or HGC-27 cells. Firstly, the transfection efficiency of SNHG4 and miR-204-5p was analyzed, and the results demonstrated that SNHG4 expression was significantly decreased after GC cells (AGS and HGC-27 cells) were transfected with siSNHG4 ( $\mathrm{P}<0.001$; Fig. 3A and B). No significant difference was observed in miR-204-5p expression in each group using the miR-204-5p inhibitor (Fig. 3C and D). The principle use of the miR-204-5p inhibitor was to competitively bind to miR-204-5p with SNHG4, resulting in a weakened effect of miR-204-5p despite displaying no effect on miR-204-5p expression. In AGS and HGC-27 cells, the relative SNHG4 expression was significantly higher in the siNC+I and lower in the siSNHG4+IC groups compared with that in the siNC+IC group; additionally, SNHG4 expression was significantly higher in the siSNHG4+I group compared with that in the siSNHG4+IC group and lower compared with that in the siNC+I group $(\mathrm{P}<0.001$; Fig. $4 \mathrm{~A}$ and $\mathrm{B})$. Furthermore, the OD value of AGS and HGC-27 cells was significantly higher in the siNC+I group and lower in siSNHG4+IC groups compared with that in the siNC+IC group, but it was significantly higher in the siSNHG4+I group compared with that in the siSNHG4+IC and lower compared with that in the siNC+I group at $48 \mathrm{~h}$ and $72 \mathrm{~h}$ $(\mathrm{P}<0.05$ and $\mathrm{P}<0.01$; Fig. $4 \mathrm{C}$ and $\mathrm{D})$. As expected, the same trend was observed from the colony formation ability of both AGS and HGC-27 cells ( $\mathrm{P}<0.001$; Fig. 4E and F). Additionally, the expression levels of cycle-associated molecules were analyzed, and the results demonstrated that the protein expression levels of PCNA and cyclin D1 were significantly increased in the siNC+I group, while they were significantly decreased in the siSNHG4+IC group, compared with those in the siNC+IC group; miR-204-5p inhibitor reversed the inhibitory effect of siSNHG4 on the PCNA and cyclin D1 expression levels ( $\mathrm{P}<0.001$; Fig. 4G and $\mathrm{H})$. In addition, apoptosis was decreased in the siNC+I group $(\mathrm{P}<0.01$; Fig. $4 \mathrm{I}$ and $\mathrm{J})$, but significantly increased in the siSNHG4+IC group $(\mathrm{P}<0.001$; Fig. 4I and J) compared with the siNC+IC group. Moreover, 

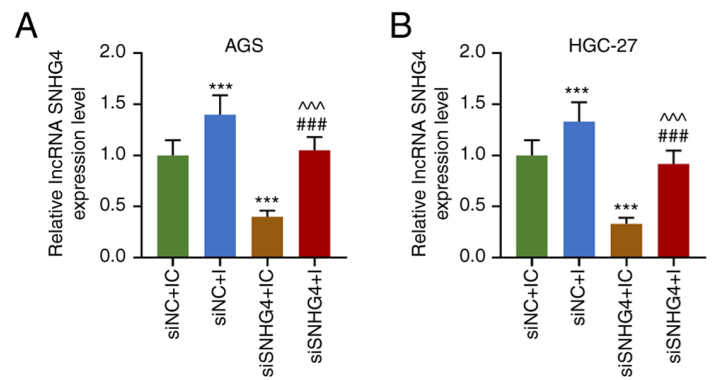

E
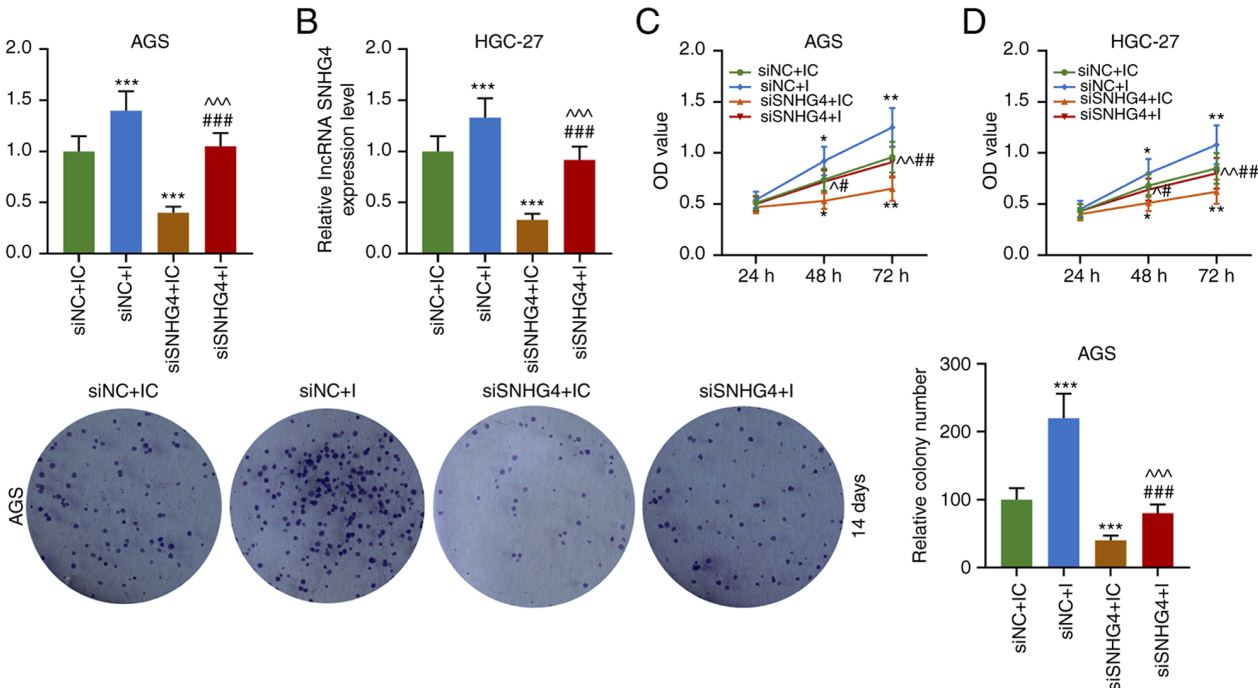

$\mathrm{F}$
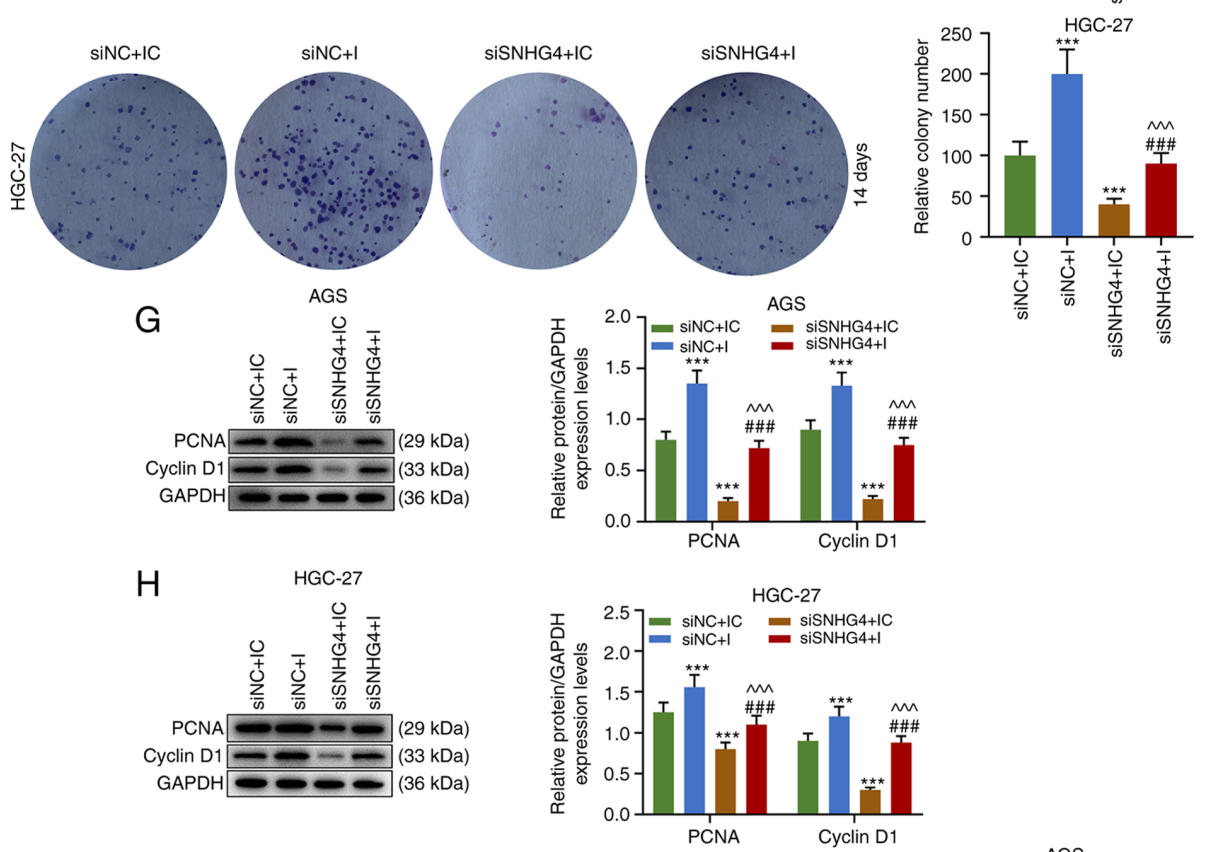
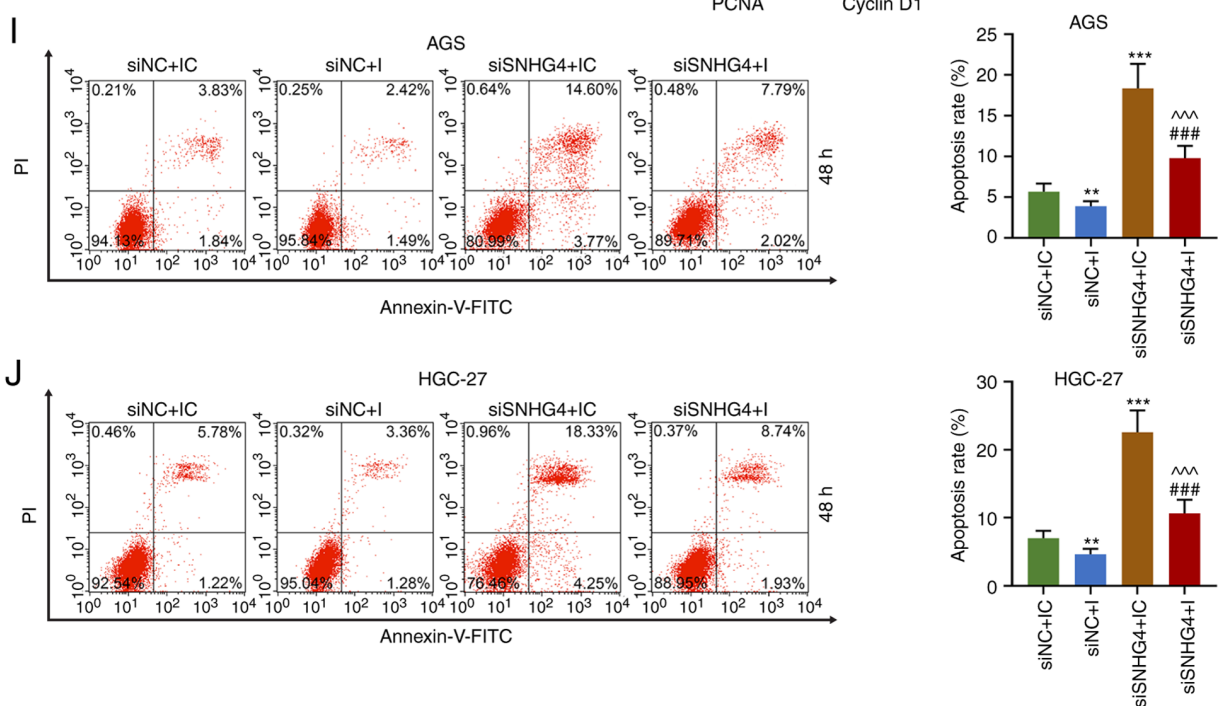

Figure 4. Downregulation of SNHG4 expression decreases the effects of miR-204-5p inhibition on the proliferation and apoptosis of gastric cancer cells. Relative SNHG4 expression levels in siNC+IC, siNC+I, siSNHG4+IC and siSNHG4+I groups in (A) AGS or (B) HGC-27 cells. OD in each group in (C) AGS or (D) HGC-27 cells. Relative colony number in each group in (E) AGS or (F) HGC-27 cells. Protein expression levels of PCNA and cyclin D1 in (G) AGS or $(\mathrm{H}) \mathrm{HGC}-27$ cells in siNC+IC, siNC+I, siSNHG4+IC and siSNHG4+I groups. Apoptosis rate of (I) AGS or (J) HGC-27 cells in each group. Bars indicate the mean \pm standard deviation. ${ }^{*} \mathrm{P}<0.05,{ }^{* *} \mathrm{P}<0.01$ and ${ }^{* * * *} \mathrm{P}<0.001$ vs. siNC+IC; ${ }^{\wedge} \mathrm{P}<0.05,{ }^{\wedge \wedge} \mathrm{P}<0.01$ and ${ }^{\wedge \wedge}{ }^{\wedge} \mathrm{P}<0.001$ vs. siNC+I; ${ }^{*} \mathrm{P}<0.05,{ }^{\# \#} \mathrm{P}<0.01$ and

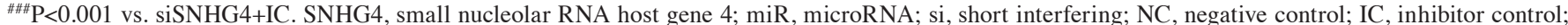
I, inhibitor; OD, optical density; PCNA, proliferating cell nuclear antigen; lncRNA, long non-coding RNA. 
A
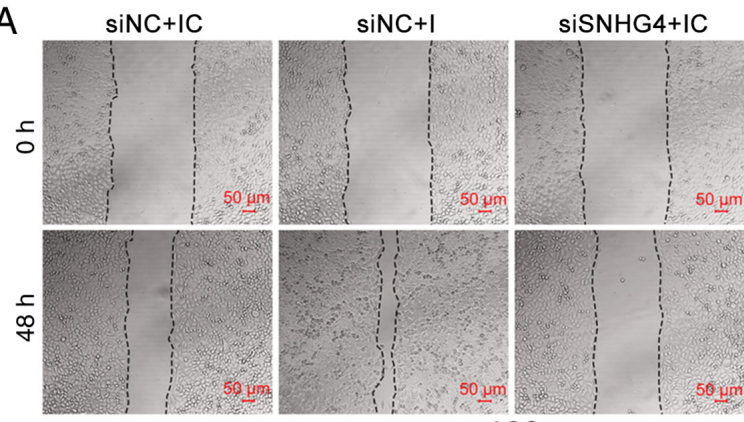

AGS

B
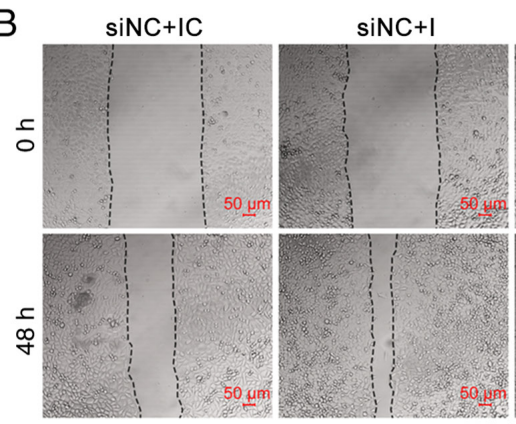

HGC-27

C
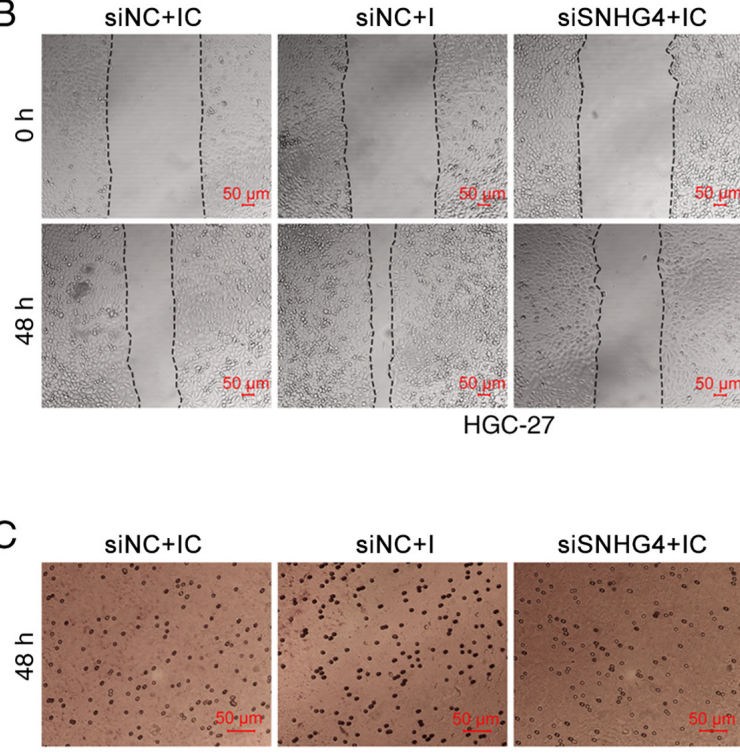

$4+$ IC
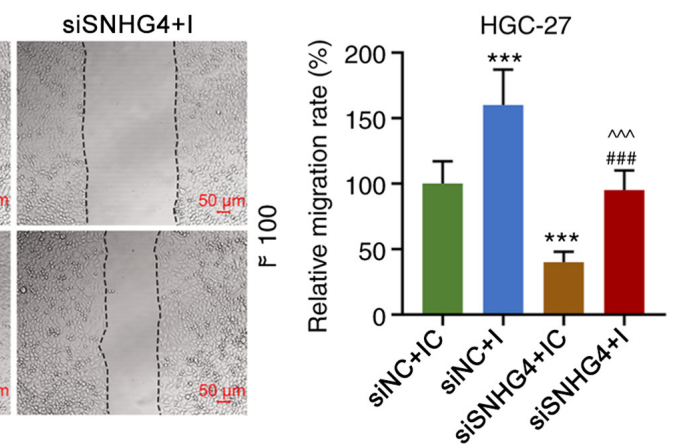

D
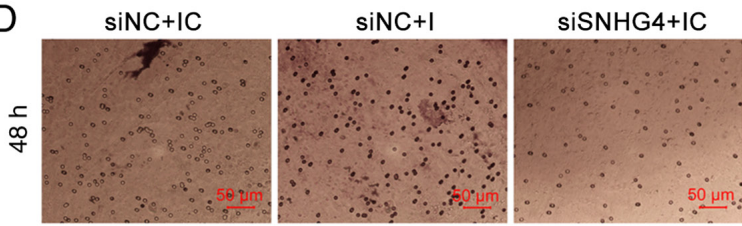

HGC-27
siSNHG4+IC

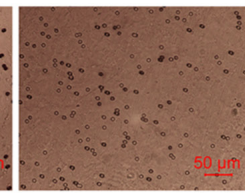

AGS

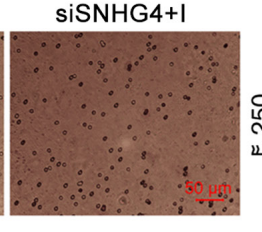

siSNHG4+1

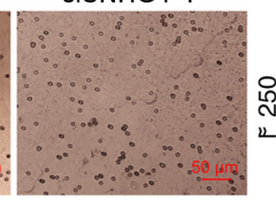

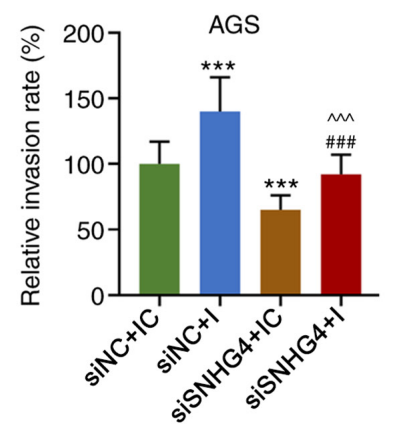
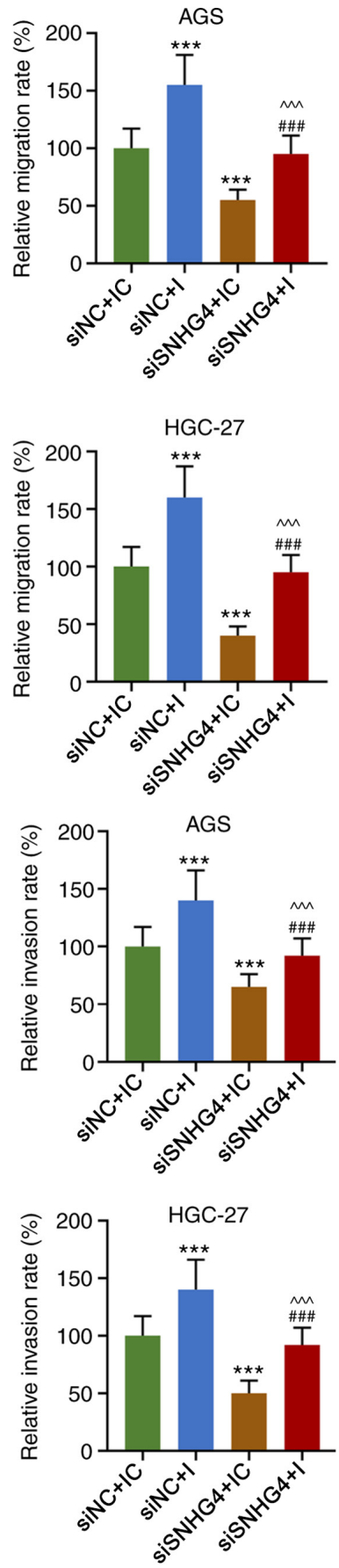

Figure 5. Downregulation of SNHG4 expression decreases the effects of miR-204-5p inhibition on the migration and invasion of gastric cancer cells. Relative migration rate of (A) AGS or (B) HGC-27 cells in siNC+IC, siNC+I, siSNHG4+IC and siSNHG4+I groups. Relative invasion rate of (C) AGS or (D) HGC-27 cells in each group. Scale bar, $50 \mu \mathrm{m}$. Bars indicate the mean \pm standard deviation. ${ }^{* * *} \mathrm{P}<0.001$ vs. siNC $+\mathrm{IC} ;{ }^{\wedge \wedge} \mathrm{P}<0.001 \mathrm{vs}$. siNC+I; ${ }^{\# \# \#} \mathrm{P}<0.001 \mathrm{vs}$. siSNHG4+IC. SNHG4, small nucleolar RNA host gene 4; miR, microRNA; si, short interfering; NC, negative control; IC, inhibitor control; I, inhibitor.

miR-204-5p inhibitor reversed siSNHG4-mediated promotion of apoptosis (Fig. 4I and J). Therefore, downregulation of miR-204-5p was able to promote the development of GC via increasing $\mathrm{GC}$ cell proliferation and decreasing apoptosis. However, downregulation of SNHG4 expression may reverse this trend caused by miR-204-5p.

Downregulation of SNHG4 expression reverses the effects of the miR-204-5p inhibitor on the migration and invasion of $G C$ cells. The migration and invasion of AGS and HGC-27 cells were investigated, and the results revealed that the migration and invasion of the cells were significantly higher in the siNC+I group and lower in the siSNHG4+IC group compared with those in the siNC+IC group, but they were significantly higher in the siSNHG4+I group compared with those in the siSNHG4+IC and lower compared with those in the siNC+I group $(\mathrm{P}<0.001$; Fig. 5A-D). The data indicated that downregulation of SNHG4 expression may decrease the migration and invasion increased by miR-204-5p inhibitor in GC cells.

Downregulation of SNHG4 expression reverses the effect of the miR-204-5p inhibitor on the epithelial-mesenchymal 

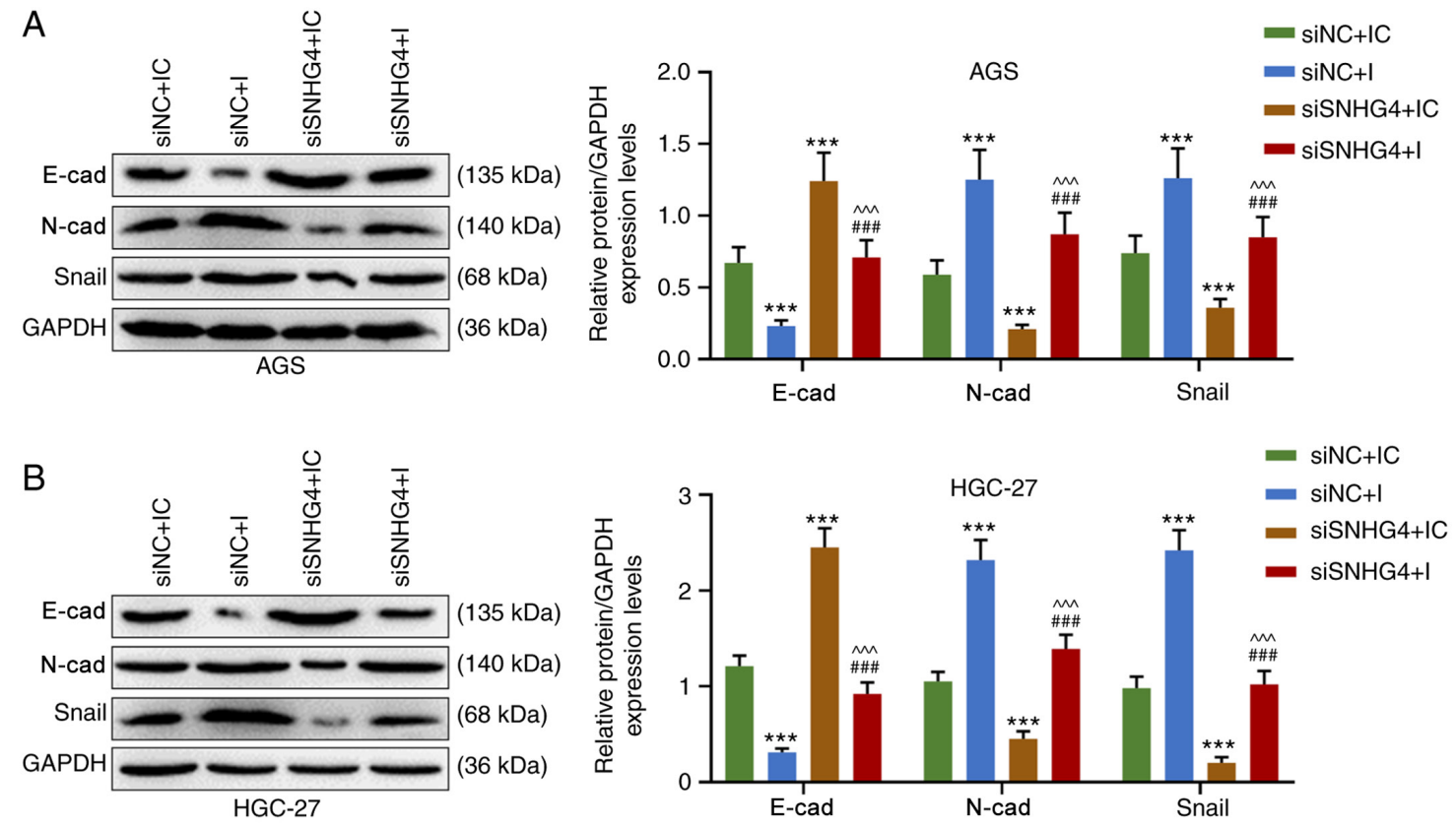

Figure 6. Downregulation of SNHG4 expression decreases the effect of miR-204-5p inhibition on the epithelial-mesenchymal transition of gastric cancer cells Protein expression levels of E-cad, N-cad and Snail in (A) AGS or (B) HGC-27 cells in siNC+IC, siNC+I, siSNHG4+IC and siSNHG4+I groups. Bars indicate the mean \pm standard deviation. ${ }^{* * *} \mathrm{P}<0.001$ vs. siNC+IC; ${ }^{\wedge \wedge} \mathrm{P}<0.001$ vs. siNC+I; ${ }^{* \# \#} \mathrm{P}<0.001$ vs. siSNHG4+IC. SNHG4, small nucleolar RNA host gene 4; miR, microRNA; cad, cadherin; si, short interfering; NC, negative control; IC, inhibitor control; I, inhibitor.

transition (EMT) of GC cells. The EMT of AGS and HGC-27 cells was detected after the treatment with siSNHG4 or miR-204-5p inhibitor. The results demonstrated that in both AGS and HGC-27 cells, the expression levels of $\mathrm{N}$-cad and Snail were significantly higher in the siNC+I and lower in the siSNHG4+IC groups compared with those in the siNC+IC group, but they were significantly higher in the siSNHG4+I group compared with those in the siSNHG4+IC and lower compared with those in the siNC+I group $(\mathrm{P}<0.001$; Fig. 6A and B). Overall, E-cad expression displayed the opposite trend compared with the expression levels of $\mathrm{N}$-cad or Snail (Fig. 6A and B). Therefore, SNHG4 downregulation may eliminate the effect of the miR-204-5p inhibitor on the EMT of GC cells.

\section{Discussion}

The present study demonstrated that SNHG4 expression was upregulated in GC and resulted in a lower survival rate. miR-204-5p expression was downregulated in GC tissues and cell lines, and was predicted to be able to interact with SNHG4; in addition, the expression levels of the two RNAs were found to be negatively correlated. Furthermore, the proliferation, apoptosis, migration, invasion and EMT increased by miR-204-5p inhibition in GC cells was counteracted by the downregulation of SNHG4 expression. The data revealed a potential mechanism explaining the development of GC.

The present study revealed that SNHG4 was highly expressed in GC tissues and cell lines, and was associated with a poor survival rate in patients with GC. Further exploration demonstrated that the downregulation of SNHG4 expression decreased the proliferation, migration and invasion of GC cells compared with those of cells without treatment; in addition, it decreased the expression levels of $\mathrm{N}$-cad and Snail, and increased E-cad expression. EMT is a process during which epithelial cells lose polarity, tight junctions, adhesion and the morphology and characteristics of cytoplasmic cells, thus gaining the ability to invade and migrate $(23,24)$. EMT serves a crucial role in tumor formation and metastasis, especially in the invasion and metastasis of tumors (25-28). In the process of EMT, the expression levels of various cell adhesion factors, such as E-cad and $\alpha$-catenin, are downregulated, while others, such as Twist, Snail, Slug and TGF- $\beta$, are upregulated (26-28). Therefore, the increased expression levels of E-cad, along with decreased expression levels of N-cad and Snail, reflect decreased EMT. Xu et al (29) revealed that, via miR-224-3p, SNHG4 acts as a promoter in osteosarcoma development and causes poor survival rates. Tang et al (30) noted that SNHG4 promoted the proliferation, migration, invasiveness and epithelial-mesenchymal transition of lung cancer cells by regulating miR-98-5p. Collectively, the aforementioned studies indicated a promoting role of SNHG4 in cancer; therefore, the present study further investigated the role of SNHG4 in gastric cancer.

The present study demonstrated that miR-204-5p could interact with SNHG4 and that miR-204-5p expression was downregulated in GC tissues and cell lines; in addition, the expression levels of the two RNAs were negatively correlated in ANTs and GC tissues. Bian et al (31) demonstrated that IncRNA UCA1 promotes the tumorigenesis of colorectal cancer via targeting miR-204-5p to inhibit its expression. Similarly, Yin et al (32) identified that miR-204-5p could target RAB22A and further restrain the biological characteristics of colorectal cancer. In papillary thyroid carcinoma, miR-204-5p inhibits the proliferation of tumor cells (33). Therefore, miR-204-5p may act as a suppressor in GC development. However, the present study revealed that SNHG4 may interact with miR-204-5p by negatively regulating miR-204-5p expression and counteracting the antitumor effects of miR-204-5p 
on the proliferation, apoptosis, colony formation, migration, invasion and EMT of GC cells. The results of the current study suggested that SNHG4 exerted its function via targeting and interacting with miR-204-5p, thus promoting the progression of GC. However, the results of the present study require validation by performing in vivo experiments. In addition, the signaling pathway regulation underlying SNHG4/miR-204-5p-mediated promotion of GC progression requires further investigation.

In conclusion, GC progression may result from a loss of regulation of SNHG4; specifically, SNHG4 upregulation may promote GC by inhibiting miR-204-5p expression. The discovery of the mechanism of this SNHG4-miR-204-5p pathway may contribute to the development of drugs against the growth of GC.

\section{Acknowledgements}

Not applicable.

\section{Funding}

No funding was received.

\section{Availability of data and materials}

The datasets used and/or analyzed during the current study are available from the corresponding author on reasonable request.

\section{Authors' contributions}

SW and WZ made substantial contributions to the conception and design of the present study. JQ and FC performed data acquisition, data analysis and interpretation. SW and WZ drafted the manuscript and critically revised it for important intellectual content. All authors read and approved the final manuscript.

\section{Ethics approval and consent to participate}

All experiments were approved by the Ethics Board of Zhuji People's Hospital (approval no. ZJ-20180215) and were in accordance with the 1964 Helsinki declaration and its later amendments or comparable ethical standards. All patients in the present study provided written informed consent.

\section{Patient consent for publication}

Not applicable.

\section{Competing interests}

The authors declare that they have no competing interests.

\section{References}

1. Van Cutsem E, Sagaert X, Topal B, Haustermans K and Prenen H: Gastric cancer. Lancet 388: 2654-2664, 2016.

2. Cai J, Niu X, Chen Y, Hu Q, Shi G, Wu H, Wang J and Yi J: Emodin-induced generation of reactive oxygen species inhibits RhoA activation to sensitize gastric carcinoma cells to anoikis. Neoplasia 10: 41-51, 2008.
3. Ferlay J, Soerjomataram I, Dikshit R, Eser S, Mathers C, Rebelo M, Parkin DM, Forman D and Bray F: Cancer incidence and mortality worldwide: Sources, methods and major patterns in GLOBOCAN 2012. Int J Cancer 136: E359-E386, 2015.

4. Sun Y and Ma L: The emerging molecular machinery and therapeutic targets of metastasis. Trends Pharmacol Sci 36: 349-359, 2015.

5. Turajlic S and Swanton C: Metastasis as an evolutionary process. Science 352: 169-175, 2016.

6. Tanabe S, Ishido K, Matsumoto T, Kosaka T, Oda I, Suzuki H, Fujisaki J, Ono H, Kawata N, Oyama T, et al: Long-term outcomes of endoscopic submucosal dissection for early gastric cancer: A multicenter collaborative study. Gastric Cancer 20 (Suppl 1): 45-52, 2017.

7. Bang YJ, Van Cutsem E, Feyereislova A, Chung HC, Shen L, Sawaki A, Lordick F, Ohtsu A, Omuro Y, Satoh T, et al; ToGA Trial Investigators: Trastuzumab in combination with chemotherapy versus chemotherapy alone for treatment of HER2-positive advanced gastric or gastro-oesophageal junction cancer (ToGA): A phase 3, open-label, randomised controlled trial. Lancet 376: 687-697, 2010.

8. Kang YK, Satoh T, Ryu MH, Chao Y, Kato K, Chung HC, Chen JS, Muro K, Kang WK, Yoshikawa T, et al: Nivolumab (ONO-4538/BMS-936558) as salvage treatment after second or later-line chemotherapy for advanced gastric or gastro-esophageal junction cancer (AGC): a double-blinded, randomized, phase III trial. J Clin Oncol 35 (Suppl 4): 2-2, 2017.

9. Xu X, Qian LJ, Su XY, He KF, Jin KT, Gu LH, Feng JG, Li GL, Zhou Q, Xu ZZ, et al: Establishment and characterization of GCSR1, a multi-drug resistant signet ring cell gastric cancer cell line. Int J Oncol 46: 2479-2487, 2015.

10. Cheng J, Kapranov P, Drenkow J, Dike S, Brubaker S, Patel S, Long J, Stern D, Tammana H, Helt G, et al: Transcriptional maps of 10 human chromosomes at 5-nucleotide resolution. Science 308: 1149-1154, 2005.

11. Birney E, Stamatoyannopoulos JA, Dutta A, Guigó R, Gingeras TR, Margulies EH, Weng Z, Snyder M, Dermitzakis ET, Thurman RE, et al; Children's Hospital Oakland Research Institute: Identification and analysis of functional elements in $1 \%$ of the human genome by the ENCODE pilot project. Nature 447: 799-816, 2007.

12. Carninci P, Kasukawa T, Katayama S, Gough J, Frith MC, Maeda N, Oyama R, Ravasi T, Lenhard B, Wells C, et al; Consortium F; RIKEN Genome Exploration Research Group and Genome Science Group: (Genome Network Project Core Group) The transcriptional landscape of the mammalian genome. Science 309: 1559-1563, 2005.

13. Geisler S and Coller J: RNA in unexpected places: Long non-coding RNA functions in diverse cellular contexts. Nat Rev Mol Cell Biol 14: 699-712, 2013

14. Hirakata S and Siomi MC: piRNA biogenesis in the germline: From transcription of piRNA genomic sources to piRNA maturation. Biochim Biophys Acta 1859: 82-92, 2016.

15. Jacquier A: The complex eukaryotic transcriptome: Unexpected pervasive transcription and novel small RNAs. Nat Rev Genet 10: 833-844, 2009.

16. Kim VN, Han J and Siomi MC: Biogenesis of small RNAs in animals. Nat Rev Mol Cell Biol 10: 126-139, 2009.

17. Clark MB, Choudhary A, Smith MA, Taft RJ, Mattick JS, Taft RJ and Mattick JS: The dark matter rises: The expanding world of regulatory RNAs. Essays Biochem 54: 1-16, 2013.

18. Li H, Hong J and Wijayakulathilaka WS: Long non-coding RNA SNHG4 promotes cervical cancer progression through regulating c-Met via targeting miR-148a-3p. Cell Cycle 18: 3313-3324, 2019.

19. Chen X, Chen Z, Yu S, Nie F, Yan S, Ma P, Chen Q, Wei C, $\mathrm{Fu} \mathrm{H}, \mathrm{Xu}$ T, et al: Long noncoding RNA LINC01234 functions as a competing endogenous RNA to regulate CBFB expression by sponging miR-204-5p in gastric cancer. Clin Cancer Res 24: 2002-2014, 2018

20. In H, Solsky I, Palis B, Langdon-Embry M, Ajani J and Sano T: Validation of the 8th edition of the AJCC TNM staging system for gastric cancer using the national cancer database. Ann Surg Oncol 24: 3683-3691, 2017.

21. Nagy Á, Lánczky A, Menyhárt O and Győrffy B: Validation of miRNA prognostic power in hepatocellular carcinoma using expression data of independent datasets. Sci Rep 8: 9227, 2018.

22. Livak KJ and Schmittgen TD: Analysis of relative gene expression data using real-time quantitative PCR and the 2(-Delta Delta C(T)) method. Methods 25: 402-408, 2001.

23. Guarino M: Epithelial-mesenchymal transition and tumour invasion. Int J Biochem Cell Biol 39: 2153-2160, 2007. 
24. Romeo E, Caserta CA, Rumio C and Marcucci F: The vicious cross-talk between tumor cells with an EMT phenotype and cells of the immune system. Cells 8: 8, 2019.

25. Thiery JP: Epithelial-mesenchymal transitions in development and pathologies. Curr Opin Cell Biol 15: 740-746, 2003.

26. Wheelock MJ, Shintani Y, Maeda M, Fukumoto Y and Johnson KR: Cadherin switching. J Cell Sci 121: 727-735, 2008.

27. Nishizuka M, Komada R and Imagawa M: Knockdown of RhoE expression enhances TGF- $\beta$-induced EMT (epithelial-to-mesenchymal transition) in cervical cancer HeLa cells. Int J Mol Sci 20 : 20, 2019.

28. Zhou J, Cheng H, Wang Z, Chen H, Suo C, Zhang H, Zhang J, Yang Y, Geng L, Gu M, et al: Bortezomib attenuates renal interstitial fibrosis in kidney transplantation via regulating the EMT induced by TNF- $\alpha$-Smurf1-Akt-mTOR-P70S6K pathway. J Cell Mol Med 23: 5390-5402, 2019.

29. Xu R, Feng F, Yu X, Liu Z and Lao L: LncRNA SNHG4 promotes tumour growth by sponging miR-224-3p and predicts poor survival and recurrence in human osteosarcoma. Cell Prolif 51: e12515, 2018

30. Tang Y, Wu L, Zhao M, Zhao G, Mao S, Wang L, Liu S and Wang X: LncRNA SNHG4 promotes the proliferation, migration, invasiveness, and epithelial-mesenchymal transition of lung cancer cells by regulating miR-98-5p. Biochem Cell Biol 97: 767-776, 2019
31. Bian Z, Jin L, Zhang J, Yin Y, Quan C, Hu Y, Feng Y, Liu H, Fei B, Mao Y, et al: LncRNA-UCA1 enhances cell proliferation and 5-fluorouracil resistance in colorectal cancer by inhibiting miR-204-5p. Sci Rep 6: 23892, 2016.

32. Yin Y, Zhang B, Wang W, Fei B, Quan C, Zhang J, Song M, Bian Z, Wang Q, Ni S, et al: miR-204-5p inhibits proliferation and invasion and enhances chemotherapeutic sensitivity of colorectal cancer cells by downregulating RAB22A. Clin Cancer Res 20: 6187-6199, 2014.

33. Liu L, Wang J, Li X, Ma J, Shi C, Zhu H, Xi Q, Zhang J, Zhao X and Gu M: MiR-204-5p suppresses cell proliferation by inhibiting IGFBP5 in papillary thyroid carcinoma. Biochem Biophys Res Commun 457: 621-626, 2015.

This work is licensed under a Creative Commons Attribution-NonCommercial-NoDerivatives 4.0 International (CC BY-NC-ND 4.0) License. 